\title{
COOPERAÇÃO INTERNACIONAL NO RECONHECIMENTO DO CONSTITUCIONALISMO GLOBAL EM TEMPOS DE PANDEMIA SANITÁRIA
}

\author{
William Paiva Marques Júnior*
}

\section{RESUMO:}

As transformações são bastante perceptíveis com o quadro pandêmico mundial causado pela Covid-19, verificando-se uma reorganização do Direito Internacional. Tem-se, portanto, uma genuína internacionalização do Direito, surgindo a necessidade de reconhecimento de um constitucionalismo global cooperativo nos tempos vivenciados como combate aos efeitos deletérios causados pela pandemia de Covid-19. Utiliza-se, como metodologia, de pesquisa do tipo bibliográfica por meio da análise de livros, artigos jurídicos, documentos internacionais, da legislação e da jurisprudência. A pesquisa é pura, de natureza qualitativa e quantitativa, com finalidade descritiva e exploratória.

PALAVRAS- CHAVE: COOPERAÇÃO INTERNACIONAL; CONSTITUCIONALISMO GLOBAL; PANDEMIA; DESAFIOS; DIREITO INTERNACIONAL.

\section{INTERNATIONAL COOPERATION IN THE RECOGNITION OF GLOBAL CONSTITUTIONALISM IN SANITARY PANDEMIC TIMES}

\begin{abstract}
:
The changes are very noticeable with the global pandemic situation caused by Covid-19, with a reorganization of international law. There is, therefore, a genuine internationalization of Law, with the need to recognize a global cooperative constitutionalism in the times experienced as combating the deleterious effects caused by the Covid-19 pandemic. Bibliographic research is used as a methodology through the analysis of books, legal articles, international documents, legislation and jurisprudence. The research is pure, of a qualitative and quantitative nature, with descriptive and exploratory purposes.
\end{abstract}

KEYWORDS: INTERNATIONAL COOPERATION; GLOBAL CONSTITUTIONALISM; PANDEMIC TIMES; CHALLENGES; INTERNATIONAL LAW.

\section{INTRODUÇÃO}

A realidade contemporânea demonstra um momento histórico ímpar, na medida em que os valores que o permearam se encontram sob de mutação. As referências sociais,

\footnotetext{
* Doutor e Mestre em Direito Constitucional pela UFC. Professor Adjunto I do Departamento de Direito Privado da Faculdade de Direito da UFC de Direito Civil II (Direito das Obrigações) e Direito Civil V (Direito das Coisas). Coordenador da Graduação em Direito da UFC (2014 a 2017). Assessor do Reitor da UFC. Docente do Programa de Pós-Graduação em Direito da UFC das disciplinas de Metodologia do Ensino Jurídico, Metodologia da Pesquisa Jurídica e Direito das Relações Internacionais e Contemporaneidade. Foi Advogado Júnior da ECT (Empresa Brasileira de Correios e Telégrafos), de 2008 a 2011. E-mail: williamarques.jr@gmail.com . Endereço postal: Avenida da Universidade, nº 2853 - Bairro: Benfica, Fortaleza - CE, CEP 60020-181- Gabinete do Reitor da UFC.
} 
jurídicas, políticas, econômicas e ambientais transformam-se com tão vigorosa rapidez e profundidade que os valores outrora vigentes não se reproduzem para as situações vindouras.

As transformações são bastante perceptíveis no plano das relações internacionais. em contexto com o quadro pandêmico mundial causado pela Covid-19, o início do sistema normativo de proteção dos direitos humanos. É como se se projetasse a vertente de um constitucionalismo global, vocacionado a proteger os direitos fundamentais e a limitar o poder do Estado, mediante a criação de um aparato internacional de proteção de direitos na cruel realidade surgida com o quadro sanitário caótico causado pelo coronavírus, por força dos influxos da cooperação internacional.

Alguns países europeus outrora exitosos no plano global em especial, França, Itália, Espanha, Grécia, encontram-se imersos em um contexto de crise política, econômica e social, que dificilmente será superado em curto prazo, especialmente no contexto dos impactos do quadro pandêmico do coronavírus (Covid-19).

$\mathrm{Na}$ contemporaneidade, observa-se que a China é o país líder no contexto das relações internacionais, em especial no crescimento econômico (embora tenha apresentado desaceleração nos últimos anos), malgrado demonstre um regime não comprometido com a democracia, a cidadania, o desenvolvimento social e os direitos humanos o que representa um vácuo de um modelo que sirva como paradigma para consolidar as transformações oriundas do constitucionalismo global.

Em um contexto de crise e defasagem estrutural no plano internacionalista, surgem as orientações oriundas da cooperação internacional e do constitucionalismo global, com repercussões na revisão dos tradicionais cânones informativos da seara externa.

Utiliza-se, como metodologia, de pesquisa do tipo bibliográfica por meio da análise de livros, artigos jurídicos, documentos nacionais e internacionais, decisões judiciais e da legislação. A pesquisa é pura e de natureza qualitativa, com finalidade descritiva e exploratória.

\section{NECESSIDADE DE COOPERAÇÃO INTERNACIONAL PARA A SUPERAÇÃO DOS IMPACTOS DA PANDEMIA DE COVID-19}

No plano do Direito Internacional, a cultura global de cooperação, embora tenha se iniciado no século XIX, dinamizou-se após a Segunda Grande Guerra, com o estabelecimento do sistema das Nações Unidas no ano de 1945. A Carta da ONU em seu artigo $1, \mathrm{n}^{\circ} .: 3$ coloca, como um de seus propósitos, conseguir uma cooperação internacional 
para resolver os problemas internacionais de caráter econômico, social, cultural ou humanitário.

De acordo com Antônio Augusto Cançado Trindade (2017, pág. 157), se, por um lado, há áreas que ainda hoje, mais do que nunca, estão a requerer urgentemente a cooperação dos Estados, como, inter alia, o problema da energia nuclear, a exploração do espaço, a proteção do meio ambiente, a questão do desarmamento, a exploração dos recursos dos oceanos, o problema da fome, os usos pacíficos da Antártida - por outro lado há que se reconhecer a intensa atividade de cooperação internacional desenvolvida nos últimos anos no seio das Nações Unidas e organizações regionais.

O multilateralismo é fundamental para a proteção central às medidas sanitárias de combate ao coronavírus na ordem jurídica internacional. A cooperação internacional facilita a construção de um processo de solidariedade global. Na visão tradicional, a soberania estatal resguarda o poder de aplicar sua lei interna às pessoas naturais e jurídicas que se encontrem sob a sua jurisdição. Não obstante, existem casos em que o bem da vida a ser tutelado ultrapassa as fronteiras estatais, evidenciando a necessidade de haver cooperação entre os entes soberanos a fim de resguardar um interesse público maior, no caso ora em comento: a saúde da população mundial.

Sobre as limitações impostas pelo Direito Internacional aos contornos da soberania na contemporaneidade, prescrevem Éric Canal-Forgues e Patrick Rambaud (2011, p. 181), enquadrada e limitada por este direito, a soberania já não confere aos Estados mais do que um feixe de competências cujas condições de exercício são por ela fixadas.

As problemáticas sanitárias oriundas da pandemia de Covid-19 não se enquadram perfeitamente nos limites territoriais fixados pelas fronteiras artificiais criadas pelo homem entre os países, motivo pelo qual a degradação da saúde da população não se submete às tradicionais limitações políticas estabelecidas. Diante da dimensão global e transfronteiriça das atividades degradadoras do vírus, surge a necessidade de cooperação internacional, compreendendo-se a defesa da saúde humana no mesmo plano, em importância, de outros valores econômicos e sociais protegidos pela ordem jurídica dos Estados. Com essa preocupação, o sistema jurídico internacional ambiental evolui na busca de uma forma de cooperação entre os Estados que possa compatibilizar o desenvolvimento econômico com a garantia da saúde humana, ou seja, a garantia de sobrevivência humana e desenvolvimento das gerações presentes e futuras, algo especialmente presente na temática contemporânea atinente aos efeitos deletérios causados pela pandemia do coronavírus. Em uma crise de 
dimensões globais, um momento em que líderes políticos e os países deveriam exercitar a solidariedade em questões sanitárias, acabam, controversamente, criando meios para excluir os povos mais vulneráveis, a partir de uma perspectiva excludente, algo que pode ser minorado por meio dos mecanismos de cooperação internacional em matéria sanitária de combate ao novo coronavírus.

Para Antônio Augusto Cançado Trindade (2017, pág. 197), o princípio do dever de cooperação internacional ganhou terreno nas últimas décadas, se levarmos em conta, e.g., a relevância da cooperação internacional em várias áreas, como, e.g., nas operações de manutenção e construção da paz dentro do âmbito do direito das Nações Unidas. A cooperação internacional intensificada tem contribuído para os desenvolvimentos impressionantes nas últimas décadas em determinados domínios do direito internacional, como, e.g., a proteção internacional dos direitos humanos e do meio ambiente humano. O princípio do dever de cooperação internacional encontra -se efetivamente relacionado ao da bona fides: pode -se, de fato, encontrar apoio expresso na jurisprudência internacional ao princípio do dever de cooperação internacional. Os princípios de direito internacional constituem conjuntamente os pilares do próprio sistema jurídico internacional.

Nessa ordem de ideias, a cooperação internacional é fundamental à proteção global dos impactos da pandemia da Covid-19 na medida em que permite que se desenvolvam as estruturas e as ações necessárias à adoção e à aplicação de políticas globais por meio de tratados internacionais, e mesmo regionais, com base na soma dos esforços de colaboração entre os diversos Estados envolvidos.

Portanto, as normas internacionais são essenciais para o exercício da cooperação entre os Estados, ou seja, a cooperação internacional só pode ser realizar efetivamente por meio de um corpo normativo - convenções, tratados, contratos- que devem ser interpretados e aplicados de forma sistemática com as normas internas de cada Estado.

Sobre direito de morte e poder sobre a vida, aduz Michel Foucault (2011, págs. 149 e 150), a situação atômica se encontra hoje no ponto de chegada desse processo: o poder de expor uma população à morte geral é o inverso do poder de garantir a outra sua permanência em vida. O princípio: poder matar para poder viver, que sustentava a tática dos combates, tornou-se princípio de estratégia entre Estados; mas a existência em questão já não é aquela — jurídica — da soberania, é outra — biológica — de uma população. Se o genocídio é, de fato, o sonho dos poderes modernos, não é por uma volta, atualmente, ao 
velho direito de matar; mas é porque o poder se situa e exerce ao nível da vida, da espécie, da raça e dos fenômenos maciços de população.

A cooperação internacional fundada na solidariedade implica na formação e manutenção de um sistema de saúde mínimo que possa salvar as pessoas da morte, não só no presente, mas em relação a evitar o colapso sanitário e sofrimento às futuras gerações.

Vaticina Yuval Noah Harari (2020, págs. 39 a 42) que a segunda decisão importante a ser confrontada é entre o isolamento nacionalista e a solidariedade global. Tanto a própria pandemia como a crise econômica resultante são problemas mundiais. Só podem ser solucionados de maneira efetiva pela cooperação internacional. A cooperação internacional é uma necessidade vital também no campo econômico. Dada a natureza global da economia e das cadeias de distribuição, se cada governo agir por conta própria, desconsiderando completamente os demais, o resultado será o caos e uma crise mais profunda. Precisa-se de um plano de ação global para já.

A cooperação internacional, portanto, visa oferecer instrumentos e condições capazes de assegurar eficácia na regulação dos novos problemas que emergem desse contexto de modificação da sociedade de risco em questões sanitárias, obrigando os Estados a enfrentarem e debaterem os impactos das atividades humanas em âmbito global na coordenação de esforços em prol do bem-estar da população mundial em um contexto de biopolítica.

Conforme aduz Michel Foucault (2005, págs. 292 e 293), a biopolítica lida com a população, e a população como problema político, como problema a um só tempo científico e político, como problema biológico e como problema de poder.

A degradação da saúde humana estabelece que a cooperação internacional assuma um valor político, social e ético da proteção humanitária, indicando-se que o dever de cooperação internacional especificamente com relação à gestão estratégica das conquistas científicas na superação dos riscos por meio do monitoramento doméstico e global pelos Estados.

Para Sidney Guerra (2019, pág. 579), apesar da diversidade de interesses dos Estados, a ideia de constitucionalização das regras de conduta da sociedade, no que se refere à proteção dos direitos humanos, é cada vez mais premente. É nesse sentido que se observa uma grande transformação em determinados conceitos e institutos que são consagrados no âmbito do Direito Internacional, como, por exemplo, a soberania dos Estados e a própria formação de tribunais internacionais para julgar matérias relativas aos direitos humanos. 
A cooperação internacional no combate à pandemia de Covid-19 ensina ao mundo a necessidade de abandonar os discursos de ódio e desigualdade, o fundamentalismo religioso, o negacionismo técnico- científico e desprezo pelos conhecimentos, avanços e pesquisas científicas, combate à disseminação de notícias falsas e desinformações, além de apontar para necessidade de investimentos em políticas públicas sanitárias, ciência e tecnologia, especialmente na democratização do acesso ao processo de imunização por meio da vacinação, buscando convergências na preservação da dignidade humana e evitando o nacionalismo vacinal.

\section{APORTES PARA O CONSTRUTO DE UM CONSTITUCIONALISMO GLOBAL}

$\mathrm{Na}$ contemporaneidade, o Estado encontra-se imerso em uma grande crise de legitimidade, uma vez que todas as rupturas ora vivenciadas terminam por causar uma grande perda da soberania e da autonomia dos Estados Nacionais em suas políticas internas. Observase que o Estado Moderno está, em sua formulação clássica de soberania absoluta, ultrapassado e em situação precária, devendo ceder espaço a um Estado diferente, consagrando, no futuro, necessariamente a democracia no campo das relações internas e internacionais.

A democracia consagrou em seu âmbito, um ideal legitimador baseado na igualdade política, participação e inclusão dos governados, bem como na possibilidade de responsabilização dos atores governamentais por meio de mecanismos de sanção e questionamentos das relações de poder. Contudo, a amplitude e consideração desses elementos podem fazer surgir várias ideias e concepções do que pode estar nesse modelo teórico. Portanto, procurando aproximar uma solução do que seria o ideal democrático, devese inicialmente definir quais os fatores que levaram um sistema a ser definido como uma aproximação desse ideal, a poliarquia, e em seguida mencionar as condições que favorecem ou não esta aproximação.

A conexão com o modelo capitalista faz com que se tenha uma visão minimalista da democracia, colocando o significado do valor democrático como o sistema no qual o povo tem a oportunidade de aceitar ou recusar as pessoas designadas para governar, como em um mercado, onde a vontade do povo é o produto e não o motor do processo político, já que o poder de decisão é adquirido através de uma luta competitiva pelos votos da população.

Os idealistas que tratam das democracias de forma abstrata, na concepção de um modelo teórico inatingível, apesar de apresentarem critérios qualitativos não conseguem quantificar a democracia no contexto do constitucionalismo global. 
À luz dos impactos jurídicos, políticos, econômicos e sociais causados pela pandemia de Covid-19, torna-se premente a revisão dos conceitos tradicionais que permeiam o poder constituinte, tais como a cidadania e a própria democracia. $\mathrm{O}$ reconhecimento jurídico da influência dos movimentos sociais insurgentes requer a racionalidade e sensibilidade de seus protagonistas na harmonização das relações estatais na constituição de novos anseios em que os direitos fundamentais recriem uma realidade atenta aos clamores sociais participativos e inclusivos em uma arena internacional cada vez mais exigente e necessitada de novas diretrizes.

A busca de um novo modelo de constitucionalismo global em tempos de pandemia por força da Covid-19, ao resgatar o valor imanente à legitimidade plasmada na pluralidade democrática e na vinculação estatal à vontade popular, rompe definitivamente com a categorização oriunda das constituições do Segundo Pós-Guerra de modo a edificar as bases de um novo parâmetro.

Constitucionalismo e democracia representam conceitos distintos. Um pode existir sem o outro. A realidade contemporânea demostra que a relação entre a democracia e a Constituição se revela como constante necessidade. O escopo fundamental da constituição moderna é a introdução de mecanismos reativos às mudanças não permitidas. No contexto do modelo imanente ao neoconstitucionalismo europeu-continental, o valor democrático é materializado por meio da democracia representativa e majoritária.

Nesse sentido, surgem os aportes necessários ao reconhecimento de um constitucionalismo supranacional e global, ultrapassando questões meramente econômicas, com preocupações voltadas para aspectos do fortalecimento dos direitos humanos, da participação social inclusiva e democrática, do Estado Social e Democrático de Direito, fundado no valor da dignidade humana (base axiológica dos direitos fundamentais).

De acordo com Flávia Piovesan (2007, págs. 10/12), no esforço de reconstituir direitos humanos do Segundo Pós-Guerra, há, de um lado, a emergência do Direito Internacional dos Direitos Humanos, e, de outro, a emergência da nova feição do Direito Constitucional Ocidental, aberto a princípios e valores, com ênfase no valor da dignidade humana. No âmbito do Direito Internacional, começa a ser delineado o sistema normativo de proteção dos direitos humanos. É como se se projetasse a vertente de um constitucionalismo global, vocacionado a proteger os direitos fundamentais e a limitar o poder do Estado, mediante a criação de um aparato internacional de proteção de direitos. Por sua vez, no âmbito do Direito Constitucional Ocidental, testemunha-se a elaboração de textos 
constitucionais abertos a princípios, dotados de elevada carga axiológica, com destaque para o valor da dignidade humana. É fortalecida a ideia de que a proteção dos direitos humanos não deve se reduzir ao domínio reservado do Estado, porque revela tema de legítimo interesse internacional. Por sua vez, essa concepção inovadora aponta para duas importantes consequências: $1^{\mathrm{a}}$-) a revisão da ideia tradicional de soberania absoluta do Estado, que passa a ser objeto de relativização, na medida em que são admitidas intervenções no plano nacional em prol da proteção dos direitos humanos- isto é, transita-se de um concepção hobbesiana de soberania, centrada no Estado, para uma concepção kantiana de soberania, centrada na cidadania universal, e $2^{\mathrm{a}}$-) a cristalização da ideia de que o indivíduo deve ter direitos protegidos na esfera internacional, na condição de sujeito de direitos.

Observa-se que a Declaração Universal dos Direitos Humanos de 1948 inaugura a concepção contemporânea dos direitos humanos tipificada pela universalidade e pela indivisibilidade desses direitos.

A universalidade é consagrada já no Preâmbulo da Declaração Universal de 1948: "Considerando que o reconhecimento da dignidade inerente a todos os membros da família humana e dos seus direitos iguais e inalienáveis constitui o fundamento da liberdade, da justiça e da paz no mundo;"

Na visão de Norberto Bobbio (2004, págs. 29 e 30), com a Declaração de 1948, tem início uma terceira e última fase, na qual a afirmação dos direitos é, ao mesmo tempo, universal e positiva: universal no sentido de que os destinatários dos princípios nela contidos não são mais apenas os cidadãos deste ou daquele Estado, mas todos os homens; positiva no sentido de que põe em movimento um processoem cujo inal os direitos do homem deverão ser não mais apenas proclamados ou apenas idealmente reconhecidos, porém efetivamente protegidos até mesmo contra o Estado que os tenha violado. No final desse processo, os direitos do cidadão terão se transformado, realmente, positivamente, em direitos do homem. $\mathrm{Ou}$, pelo menos, serão os direitos do cidadão daquela cidade que não tem fronteiras, porque compreende toda a humanidade; ou, em outras palavras, serão os direitos do homem enquanto direitos dos cidadãos do mundo. A Declaração Universal contém em germe a síntese de um movimento dialético, que começa pela universalidade abstrata dos direitos naturais, transfigura-se na particularidade concreta dos direitos positivos, e termina na universalidade não mais abstrata, mas também ela concreta, dos direitos positivos universais.

O intitulado Sistema Internacional de Proteção dos Direitos Humanos, por intermédio do sistema global e de sistemas regionais. O Sistema Global de Direitos Humanos 
apresenta como protagonista as Nações Unidas - ONU, e tem como marco a Declaração dos Direitos Humanos de 1948, também é configurado por meio de vários outros documentos, como o Pacto Internacional sobre Direitos Civis e Político (1966), o Pacto Internacional sobre Direitos Econômicos, Sociais e Culturais (1966), a Convenção pela Eliminação de Todas as Formas de Discriminação Racial (1965) e de Discriminação contra a Mulher (1979), a Convenção sobre os Direitos da Criança (1989), dentre outros. A adesão a esses tratados pelos Estados membros tem impulsionado a expansão dos Direitos Humanos, inclusive por intermédio da criação de mecanismos e legislações no domínio interno. O desenvolvimento dos Direitos Humanos nos ordenamentos jurídicos nacionais revela-se significativo, com uma trajetória promissora, fato que se vislumbra elemento propulsor para o constructo de um constitucionalismo global.

O constitucionalismo global exprime como desiderato o cumprimento das genuínas funções para as quais as constituições contemporâneas foram projetadas, quais sejam: (1) criação de mecanismos que evitem regimes liberticidas (tais como as ditaduras, tão frequentes na história sul-americana dos Séculos XIX e XX); (2) evitar a subalternização e a invisibilização de seres humanos (a exemplo das escravaturas, inicialmente de indígenas e, após, de negros africanos, que permearam por longos séculos a América do Sul); (3) atribuição de poderes sancionatórios nas situações de infringência aos seus valores diretivos.

Para José Joaquim Gomes Canotilho (2006, pág. 1.370), os traços caracterizadores do constitucionalismo global são os seguintes: (1) alicerçamento do sistema jurídico-político internacional não apenas no clássico paradigma das relações internacionais entre estados (paradigma hobbesiano/wesfalliano, na tradição ocidental) mas no novo paradigma centrado nas relações entre Estado/povo (as populações dos próprios Estados); (2) emergência de um jus cogens internacional materialmente informado por valores, princípios e regras internacionais progressivamente plasmados em declarações e documentos internacionais e (3) tendencial elevação da dignidade humana a pressuposto ineliminável de todos os constitucionalismos.

Partindo-se da premissa de que o constitucionalismo não representa, necessariamente, a exaltação dos princípios da Constituição de um dado país, isto porque ele existe independentemente e além dela. Sua qualidade essencial, perante o Estado nacional, é a limitação do poder político aos seus aspectos jurídicos, sendo contrário ao governo arbitrário. Outra característica fundamental é a garantia dos direitos fundamentais, oriundos dos direitos humanos e da dignidade humana. 
Entende-se que uma das consequências da internacionalização do sistema constitucional é o seu efeito diminuidor dos poderes políticos do estado. Processos que ocorrem em decorrência da interferência da esfera internacional sobre a estrutura doméstica geram a transferência dos debates políticos para as instituições internacionais, onde as esferas de governo e de governança se confundem.

As interações entre os sistemas nacionais e internacionais podem ser resolvidas, por meio de um sistema de visão singular. Isto significa que um dilema de hierarquia seria criado posteriormente, de forma a determinar qual o conjunto de regras é superior ao outro. Por outro lado, uma abordagem dual (ou plural) parece ser mais pertinente. O Direito Constitucional Universal é pouco provável que venha a existir a curto prazo, devido à natureza inorgânica da atual fragmentação da sociedade universal em um número de comunidades políticas separadas. A estrutura inorgânica de Direito Internacional geral, a natureza inorgânica da sua formação normativa, sua forma particular e seus processos de aplicação do direito da sociedade internacional buscam estabelecer regras jurídicas internacionais em um sentido amplo. Isso força os sistemas a darem uma volta em torno de si e interagir em sua própria maneira particular. Essa interação contínua de ambos os sistemas internacionais e nacionais tem feito com que a norma doméstica passe a incorporar a agenda internacional por intermédio de tratados ou princípios constitucionais não escritas (ou legislação ad hoc).

O constitucionalismo global pode ser identificado como o surgimento de elementos constitucionais na ordem jurídica internacional. Mesmo que não haja constituição internacional, existem valores que são criados por meio do processo de fertilização cruzada, ora analisado.

Isto posto, nesta nova estrutura proposta, governos e jurisdições ajustam o exercício de sua função soberana do Estado, que passa a atuar conforme esta nova realidade. Portanto, esta nova estratégia não deve ser vista como um processo de erosão soberana, mas como a resposta à nova ordem internacional que se apresenta no contexto dos efeitos deletérios causados pela pandemia de Covid-19.

Observa-se, com efeito, o fato de que também no Direito Internacional se pode falar em constitucionalismo. Isso porque, com esteio na preocupação de uma nova situação de guerra com globais contornos, desde os anos de 1950 (momento histórico do recrudescimento da Guerra Fria), diversos foram os tratados, os quais, ainda que restritos às questões econômicas, visavam à integração entre os Estados, até mesmo o objetivo de intervir nas 
políticas internas dos países, que passaram a renunciar a uma parcela de sua soberania para cooperar e colaborar em sede de políticas externas e de segurança, dentre diversos outros aspectos.

Neste panorama com tantas divergências, surge a discussão acerca de uma Constituição supranacional, que, apesar das opiniões divergentes, contribui para a afirmação da existência de um constitucionalismo global. Isso porque a possibilidade de existir um parâmetro de consensualidade entre os povos já significa que há um nível mínimo de entendimento no estabelecimento de limites às arbitrariedades no plano das relações internacionais, com a perspectiva de se observar a primazia do valor da dignidade humana, como paradigma diretivo do constitucionalismo contemporâneo, nas esferas nacional e global.

Para José Joaquim Gomes Canotilho (2006, pág. 1.372), qualquer que seja a incerteza perante a ideia de um standard mínimo humanitário e quaisquer que sejam as dificuldades em torno de um sistema jurídico internacional de defesa de direitos humanos, sempre se terá de admitir a vantagem destes postulados e reconhecer que o poder constituinte soberano criador das constituições está hoje longe de ser um sistema autônomo que gravita à órbita da soberania do Estado. A abertura ao Direito Internacional exige a observância de princípios materiais de política e Direito Internacional tendencialmente informadores do Direito Constitucional interno.

Verifica-se a existência do constitucionalismo global como mecanismo imanente à proteção e promoção da democracia, da paz e dos direitos humanos fundamentais, não apenas restrito aos tratados e constituições supranacionais que venham a ser escritos, mas também no reconhecimento da validade de normas internas estatais, com o reconhecimento de uma nova ordem jurídico-política no âmbito das relações internacionais, reconhecendo a necessidade de superação dos impactos causados pelo novo coronavírus em escala mundial, especialmente no que concerne à valorização da democracia participativa como elemento fundante da organização estatal.

Construída em uma concepção de Estado moderno, o desenvolvimento da democracia liberal como verificado na contemporaneidade, ocorreu em grande parte do globo em um pequeno espaço de tempo. Define-se esse Estado-Nacional moderno como o aparato político, com distinção entre governante e governado, com suprema jurisdição sobre uma dada área territorial, apoiado por uma posse do monopólio do poder coercitivo, baseado em uma relação tida como legítima. Os principais elementos desse conceito então são: a territorialidade, o monopólio do controle coercitivo, uma estrutura de poder despersonalizada 
e uma posse de poder legítimo.

O conceito de Estado parece estar sofrendo, junto com o sistema democrático que o que sustenta, nova fase de mutação. Simultaneamente à mutação do conceito de Estado e o surgimento de novas instâncias de poder público, surge também a deterioração da adesão popular as até então sólidas instituições representativas democráticas.

A realidade contemporânea torna necessária uma reavaliação da teoria democrática e por consequência uma reavaliação dos conceitos de legitimidade e de accountability dos Estados atuais, que claramente não são mais adequados aos processos de globalização (e de regionalização) presentes.

Os processos sociais, políticos e econômicos têm feito com que os Estados cedam cada vez mais esferas de competências, antes exclusivamente suas, às organizações e instituições internacionais, tornando-se cada vez mais dependentes de regras e decisões estranhas a sua política doméstica. O questionamento que logicamente decorre desta situação é se o poder, decisões e ações destas forças além do, ou superiores ao Estado Nacional, são ou não legítimas através do dito referencial teórico moderno do que seria democracia (em outras palavras, segundo a teoria democrática representativa).

A evolução da democracia limitada ao âmbito da cidade (direta) à democracia em contexto nacional (representativa) parece encontrar situação análoga a sua no presente contexto de expansão global. Como o Estado aparenta tornar-se insuficiente em determinados âmbitos de atuação, ocorre uma nova transformação democrática, partindo do Estado-nacional e evoluindo para o contexto transnacional.

A ideia de um constitucionalismo global remete-se ao fato de que o EstadoNação, como anteriormente concebido no exercício de sua soberania, não consegue responder à demanda do estado administrativo e sua interação com a sociedade civil e a economia capitalista global. Essa relação passa a ser mediada com base na integração entre Estados (organizações internacionais; instrumentos multilaterais; comunidades integradas). O Estado Constitucional Moderno não apenas se relaciona política, econômica e socialmente com outros Estados, mas se submete ao controle de organismos externos transferindo a estes poderes e competência jurisdicional.

O constitucionalismo global abarca uma agenda política voltada à aplicação do Estado de Direito, separação de Poderes (e da Teoria dos checks and balances), promoção e proteção dos direitos humanos e do valor democrático.

De acordo com Norberto Bobbio (2004, pág. 96), os direitos do homem, que 
tinham sido e continuam a ser afirmados nas constituições dos Estados particulares, são hoje reconhecidos e solenemente proclamados no âmbito da comunidade internacional, com uma consequência que abalou literalmente a doutrina e a prática do Direito Internacional: todo indivíduo foi elevado a sujeito potencial da comunidade internacional, cujos sujeitos até agora considerados eram, eminentemente os Estados soberanos. Desse modo, o direito das gentes foi transformado em direito das gentes e dos indivíduos; e ao lado do Direito Internacional como direito público externo, o jus publicum europaeum, está surgindo um outro direito, denominado de "cosmopolita", de acordo com as palavras de Kant.

As relações contemporâneas demonstram a existência de vários fatores que tornam o pluralismo jurídico uma realidade no contexto internacional que faz surgir o constitucionalismo global, ante o reconhecimento dos seguintes fatores: (1) do multiculturalismo; (2) de intensas transformações econômicas (contexto de crise na Europa e nos Estados Unidos e a consequente ascensão chinesa); (3) multiplicação de conflitos (notadamente no tocante aos ataques terroristas cada vez mais frequentes, por motivos de intolerância étnica, religiosa e política); e (4) do aprofundamento das assimetrias sociais e econômicas por força da pandemia de covid-19.

Mecanismos de democracia participativa podem ser exercidos nos mais diversos níveis, tanto nos limites internos dos Estados, bem como nas organizações não governamentais ou indivíduos e no plano das relações internacionais.

Observa-se, portanto, que o modo de compreender a democracia contemporânea tem sua base na ideia do Contrato Social de Rousseau, no qual o núcleo de origem e fim último do poder político é o povo. Não se pode fechar à via democrática e constitucional no âmbito interno e nas instâncias internacionais, sob pena de retrocesso às conquistas obtidas na evolução do Estado de Direito.

A democratização no plano do constitucionalismo global se traduz na ideia de incremento da participação dos indivíduos na seara internacional, tendo como escopo a obtenção de legitimidade e estabelecendo as bases da denominada democracia constitucional.

Como desafio à democracia no plano do constitucionalismo observa-se que o valor democrático revela-se em parâmetros desiguais no âmbito dos diversos sistemas estatais.

Não é tarefa fácil tratar de um sistema constitucional global que se pretenda democrático, partindo-se da premissa mediante a qual muitas das unidades políticas estatais ainda caminham a passos lentos nesse campo, ou, em alguns casos, infelizmente retrocedem a 
passos largos, gerando profundos conflitos sociais.

Observe-se o escólio de Dieter Grimm (2007, p. 60/61), acerca do multiculturalismo e dos direitos fundamentais, ao exprimir que a integração difere da assimilação em que não espera dos imigrantes um ajuste total aos valores e modos de vida da sociedade do país de acolhimento. De uma plena liberdade cultural se diferencia em que não renuncia a uma abertura por parte deles a uma cultura do país de acolhida. A sociedade beneficiária, assim, torna-se mais pluralista, mas não tem que temer que radicalmente pôr em causa os seus valores fundamentais. A integração não é, portanto, um processo unidirecional em que o esforço de adaptação é para ser feito apenas por imigrantes. Tampouco, porém, é um processo de abordagens equivalentes. Mesmo aceitando a noção de que a sociedade do país de acolhimento se transforma para a integração. Enquanto se exige dos cidadãos nacionais apenas o reconhecimento das peculiaridades dos outros, para os imigrantes, é uma prática dosada de aprendizagem.

Acresce José Joaquim Gomes Canotilho (2006, pág. 26) a ideação de que as novas formas de modernidade política e econômica obrigam os cultores do Direito Constitucional a prestarem mais atenção a certos problemas, como os da crise de representação, do envolvimento dos direitos constitucionais nacionais pelo emergente Direito Constitucional Global ou Internacional e pelo já vigente Direito Constitucional Comunitário, e da erupção de novos direitos e de novos deveres intimamente relacionados com a liberdade e dignidade da pessoa humana e com os outros seres da comunidade biótica ("direitos fundamentais dos seres vivos"). Acrescentem-se, ainda, os problemas da "reinvenção do território" conducentes à releitura das obras sobre "federalismo" e "antifederalismo" e à sugestão de novos fenótipos organizatórios de comunidades supranacionais (União Europeia, MERCOSUL, NAFTA).

Os ideários representados pela democracia e pelos direitos humanos surgem como os elementos unificadores do Direito Constitucional Global, suplantando as diferenças econômicas, políticas, ideológicas que criam as assimetrias entre as nações, principalmente a partir dos impactos danosos oriundos da pandemia do novo coronavírus.

Os valores propugnados pela democracia e pelos direitos humanos repercutem em escala mundial, quando transcendem a perspectiva meramente nacional para ostentar uma dimensão internacional no plano institucional.

O discurso dos direitos humanos transforma-se em supedâneo para o exercício da liberdade em todos os seus matizes, transformando-se em programa político daqueles que buscam a materialização de seus ideais por meio da revolução. 
A pós-modernidade apresenta como contexto jurídico o reconhecimento dos direitos humanos além de um discurso meramente filosófico, mas principalmente aplicado pelas cortes internacionais, ora na defesa de grupos minoritários (tais como os indígenas) e em outros momentos como justificativa para a correção de atos estatais.

Neste sentido, deve-se ressaltar o disposto no Art. $5^{\circ}$ - da Convenção de Viena, de 1993, que reconhece a universalidade, indivisibilidade, interdependência e inter-relação dos direitos humanos.

A conjuntura atual no plano das relações internacionais demonstra a primazia dos direitos humanos como elemento fundante do constitucionalismo global, de modo a refletir em uma releitura de tradicionais conceitos do Direito Constitucional e do Direito Internacional, tais como a soberania, a cidadania e a democracia.

No contexto das relações internacionais contemporâneas, a delimitação conceitual da soberania é revisitada nos aspectos internos e externos do Estado- Nação a partir, com origem nas mutações advindas com o processo de globalização do constitucionalismo e dos direitos humanos.

Gerardo Pisarello (2007, p. 171) propõe a ideação de que emerge com maior força do que nunca a necessidade de um constitucionalismo global garantista no contexto mundial, capaz de coordenar suas demandas em variados níveis: planetárias, regionais, estatais e, principalmente, locais, sem sacrificar por isso nenhuma delas. Este não seria, obviamente, um mero cosmopolitismo fugitivo, direcionado à liquidação das diferenças nacionais ou dos elementos clássicos do Estado constitucional, mas o lançamento de uma nova ideia do Direito, ao permitir que eventuais sobreposições entre os sistemas jurídicos, sem ter que assumir necessariamente uma subordinação rígida de uns sobre os outros, ou com relação a sistemas de terceiros. Isso, de fato, favoreceria a convivência multicultural; como técnica de orientação, permitiria o controle constitucional e os limites dos poderes em uma direção que poderia oferecer respostas internacionais para os problemas internacionais.

No contexto do constitucionalismo contemporâneo, observa-se o acúmulo de promessas contidas em textos constitucionais não cumpridas pelos poderes constituídos, ao produzir expectativas frustradas e disseminar a ideia consoante a qual as constituições são alheias à realidade social e não foram feitas para a sua realização, ideologia esta surgida desde a ausência de efetividade normativa, bem como do divórcio entre o plano normativo e as relações interpessoais. 
Observa-se que a realidade no mundo posterior à Covid-19 plasma as linhas mestras dessa nova faceta do constitucionalismo que se propõe transformadora das relações institucionais. Conquanto as divergências contingenciais, as diretrizes futuras exprimem aspectos comuns no rompimento de uma ordem jurídico-constitucional anterior e servem de paradigma no constructo do constitucionalismo global (de nítido viés inclusivo, participativo e democrático).

\section{NECESSIDADE DE RECONHECIMENTO DO CONSTITUCIONALISMO GLOBAL EM TEMPOS DE PANDEMIA SANITÁRIA}

Conforme dados divulgados pela Organização Pan-Americana da Saúde (OPAS, 2021, online), a Organização Mundial da Saúde (OMS) declarou, em 30 de janeiro de 2020, que o surto da doença causada pelo novo Coronavírus (COVID-19) constitui uma Emergência de Saúde Pública de Importância Internacional - o mais alto nível de alerta da Organização, conforme previsto no Regulamento Sanitário Internacional. Em 11 de março de 2020, a COVID-19 foi caracterizada pela OMS como uma pandemia, com milhares de mortos em todo o Planeta.

Em 30 de janeiro de 2020, a OMS (OPAS, 2021, online) declarou que o surto do novo coronavírus constitui uma Emergência de Saúde Pública de Importância Internacional (ESPII) - o mais alto nível de alerta da Organização, conforme previsto no Regulamento Sanitário Internacional. Essa decisão buscou aprimorar a coordenação, a cooperação e a solidariedade global para interromper a propagação do vírus. Essa decisão aprimora a coordenação, a cooperação e a solidariedade global para interromper a propagação do vírus.

Sobre a necessidade de construção de um processo de solidariedade global, Stefano Rodotà $(2016$, p. 4) entende que, nos tempos difíceis é a força das coisas que faz referência a princípios que nos permitem escapar à contingência e à lógica nua e crua do poder, redescobrindo uma raiz profunda da solidariedade como sinal de não agressão entre os homens, como necessidade ineliminável.

A realidade é dinâmica e os desafios são enormes na tentativa de reversão desse grave e doloroso quadro. Surgiram novas mutações do vírus e a vacinação ainda é incipiente na maioria dos países do globo, devendo criar-se um quadro de solidariedade global para combate ao quadro caótico de ausência de meios verificada em grande parte do mundo. A cada dia surgem novos desafios e muitos países apresentam uma completa ausência de diretrizes claras e congruentes na necessidade de combate à Covid-19. 
Consoante esposado por Amartya Sen (2011, págs. 319 e 320), é razoável sustentar que as decisões sobre saúde pública com muita frequência respondem inadequadamente ao sofrimento real dos pacientes e à experiência de cura. Por outro lado, na avaliação desse debate, presente tanto nas discussões passadas como nas contemporâneas, as extensas limitações da perspectiva interna também devem ser consideradas. Mesmo que para a avaliação sensorial a prioridade da visão interna dificilmente possa ser contestada, a prática médica não se ocupa exclusivamente da dimensão sensorial da má saúde, por mais importante que seja. Um problema da dependência da própria opinião do paciente sobre assuntos médicos reside no fato de que a visão interna do paciente pode estar seriamente limitada por seu conhecimento e experiência social. Uma pessoa criada em uma comunidade com um grande número de doenças ou poucas instalações médicas tende a considerar alguns sintomas como "normais" mesmo quando são clinicamente evitáveis. Como os desejos e os prazeres adaptativos, há aqui também uma questão de adaptação às circunstâncias sociais, com consequências bastante obscuras.

A gravidade da emergência causada pela pandemia do Covid-19 exige das autoridades mundiais, em todos os níveis de governo, a efetivação concreta da proteção à saúde pública, com a adoção de todas as medidas possíveis para o apoio e manutenção das políticas públicas sanitárias. Nesse contexto, o constitucionalismo global prevê princípios e regras de competência no tocante à proteção da saúde pública uma vez que o direito à vida aparece como consequência imediata da consagração da dignidade da pessoa humana na qualidade de um de seus fundamentos basilares.

Para Luigi Ferrajoli (2020, p. 67), as funções de garantia, não apenas as jurisdicionais ou secundárias, mas também as administrativas ou primárias, como escola, assistência médica e previdência, são legitimadas por sua sujeição à lei e, em particular, aos direitos fundamentais. No entanto, aconteceu que as funções de garantia primária - educação, saúde pública e similares - que não existiam na época de Montesquieu, desenvolveram-se, com a construção do estado de bem-estar social, dentro daquele grande contêiner que é a Administração Pública, que depende do poder executivo, uma vez que certamente não pode ser colocada dentro dos poderes legislativos ou do judiciário. Mas é claro que a sua fonte de legitimação não é do tipo representativo ou majoritário, mas sim contra-majoritária, residindo nos direitos fundamentais de todos como limites que evidenciam os poderes das maiorias.

$\mathrm{O}$ desafio que a situação atual coloca à sociedade mundial e às autoridades públicas globais é da mais elevada gravidade, e não pode ser minimizado. A pandemia de 
COVID-19 (Coronavírus) é uma ameaça real e iminente, que irá extenuar a capacidade operacional de sobrevivência humana e, com consequências desastrosas para a população, caso não sejam adotadas medidas corretas e concretas de efeito imediato e eficaz. . Nesse contexto, o reconhecimento de um constitucionalismo global lança luzes sobre a solução dos obstáculos impostos pela cruel realidade.

No diagnóstico de Yuval Noah Harari (2020), neste momento de crise, a batalha crucial está sendo travada dentro da própria humanidade. Se a pandemia criar mais desunião e desconfiança entre os seres humanos, o vírus terá obtido sua maior vitória. Quando os humanos brigam, os vírus se duplicam. Em troca, se a epidemia produzir uma maior cooperação mundial, essa será uma vitória não só contra o coronavírus, mas contra todos os futuros agentes patogênicos.

$\mathrm{Na}$ presente crise humanitária, alguns governos assumiram condutas equivocadas e erráticas, denotando muitas falhas na luta contra a pandemia, incluindo manipulação de dados e discursos falaciosos, irresponsáveis e distorcidos, implicando em aumento considerável do número de óbitos. Nesse contexto, o constitucionalismo global assume um papel vetorial na solução desses problemas metodológicos ao optar pela valorização da vida com dignidade.

Ante essa complexa e desafiadora realidade imposta pela Covid-19, Boaventura de Sousa Santos (2020) defende: "Só com uma nova articulação entre os processos políticos e os processos civilizatórios será possível começar a pensar uma sociedade em que a humanidade assuma uma posição mais humilde no planeta que habita".

No plano prospectivo, portanto, a humanidade se vê diante da encruzilhada prevista por Edgar Morin (2011, pág. 74), tantos problemas dramaticamente unidos fazem-nos pensar que o mundo não só está em crise; encontra-se em violento estado no qual se enfrentam as forças da morte e as forças da vida, que se pode chamar de "agonia". Ainda que solidários, os humanos permanecem inimigos uns dos outros, e o desencadeamento de ódios de raça, religião, ideologia conduz sempre a guerras, massacres, torturas, ódios, desprezo. Os processos são destruidores do mundo antigo, aqui, multimilenar, ali, multissecular. A humanidade não consegue gerar a Humanidade. Não sabemos ainda se se trata só da agonia de um velho mundo - prenúncio do novo nascimento- ou da agonia mortal. Nova consciência começa a surgir: a humanidade é conduzida para uma aventura desconhecida.

\section{CONSIDERAÇÕES FINAIS}

A cooperação no plano do constitucionalismo global se traduz na ideia de 
incremento da participação dos indivíduos na seara internacional, tendo como escopo a obtenção de legitimidade e estabelecendo as bases da denominada democracia constitucional.

Não é tarefa fácil tratar de um sistema constitucional global que se pretenda cooperativo, solidário e democrático, partindo-se da premissa mediante a qual muitas das unidades políticas estatais ainda caminham a passos lentos nesse campo, ou, em alguns casos, infelizmente retrocedem a passos largos, gerando profundos conflitos sociais.

Os ideários representados pela cooperação democrática e pelos direitos humanos surgem como os elementos unificadores do Direito Constitucional Global, suplantando as diferenças econômicas, políticas, ideológicas que criam as assimetrias entre as nações, principalmente a partir dos impactos danosos oriundos da pandemia do novo coronavírus.

As transformações são bastante perceptíveis no plano das relações internacionais. em contexto com o quadro pandêmico mundial causado pela Covid-19, o início do sistema normativo de proteção dos direitos humanos. É como se se projetasse a vertente de um constitucionalismo global, vocacionado a proteger os direitos fundamentais e a limitar o poder do Estado, mediante a criação de um aparato internacional de proteção de direitos na cruel realidade surgida com o quadro sanitário caótico causado pelo coronavírus.

Os valores propugnados pela democracia e pelos direitos humanos repercutem em escala mundial, quando transcendem a perspectiva meramente nacional para ostentar uma dimensão internacional no plano institucional.

Observa-se que a realidade no mundo posterior à Covid-19 plasma as linhas mestras dessa nova faceta do constitucionalismo global que se propõe transformadora das relações institucionais. Conquanto as divergências contingenciais, são expressos aspectos comuns no rompimento de uma ordem jurídico-constitucional anterior e servem de paradigma no constructo do constitucionalismo global (de nítido viés inclusivo, participativo e democrático).

A realidade é dinâmica e os desafios são enormes na tentativa de reversão desse grave e doloroso quadro. Surgiram novas mutações do vírus e a vacinação ainda é incipiente na maioria dos países do globo, devendo criar-se um quadro de solidariedade global para combate ao quadro caótico de ausência de meios verificada em grande parte do mundo. A cada dia surgem novos desafios e muitos países apresentam uma completa ausência de diretrizes claras e congruentes na necessidade de combate à Covid-19.

$\mathrm{O}$ desafio que a situação atual coloca à sociedade mundial e às autoridades públicas globais é da mais elevada gravidade, e não pode ser minimizado. A pandemia de 
COVID-19 (Coronavírus) é uma ameaça real e iminente, que irá extenuar a capacidade operacional de sobrevivência humana e, com consequências desastrosas para a população, caso não sejam adotadas medidas corretas e concretas de efeito imediato e eficaz. Nesse contexto, o reconhecimento de um constitucionalismo global e cooperativo lança luzes sobre a solução dos obstáculos impostos pela cruel realidade e ensina ao mundo a necessidade de investimentos em políticas públicas sanitárias, ciência e tecnologia, especialmente na democratização do acesso ao processo de imunização por meio da vacinação, buscando convergências na preservação da dignidade humana e evitando o nacionalismo vacinal.

\section{REFERÊNCIAS BIBLIOGRÁFICAS}

BOBBIO, Norberto. A era dos direitos. Tradução: Carlos Nelson Coutinho. 1ª - edição. 13ª reimpressão. Rio de Janeiro: Elsevier, 2004.

CANAL-FORGUES, Éric. RAMBAUD, Patrick. Droit international public. 2e- édition. Paris: Champs Université, 2011.

CANOTILHO, José Joaquim Gomes. Direito Constitucional e Teoria da Constituição. $7^{\text {a }}$ edição. $2^{\mathrm{a}}$ - Reimpressão. Coimbra: Almedina, 2.006.

FERRAJOLI, Luigi. Constitucionalismo além do Estado. Palestra proferida no I Encontro Virtual do CONPEDI. Tradução: Sandra Regina Martini. Florianópolis: CONPEDI, 2020.

FOUCAULT, Michel. Em defesa da sociedade: curso no Collège de France (1975/1976). Tradução: Maria Ermantina Galvão. 1ª - edição. 4- tiragem. São Paulo: Martins Fontes, 2.005. FOUCAULT, Michel. História da sexualidade I: a vontade de saber. Tradução: Maria Thereza da Costa Albuquerque e J. A. Guilhon Albuquerque. 1'- edição. 23 $3^{\mathrm{a}}$ - reimpressão. São Paulo: Edições Graal LTDA, 2011.

GRIMM, Dieter. Multiculturalidad y derechos fundamentales. IN: DENNINGER, Erhard y GRIMM, Dieter. Derecho constitucional para la sociedad multicultural. Madrid: Editorial Trotta, 2007.

GUERRA, Sidney. Curso de Direito Internacional Público. 12ª - edição. São Paulo: Saraiva Educação, 2019.

HARARI, Yuval Noah. Na batalha contra o coronavírus, faltam líderes à humanidade. Tradução: Odorico Leal. São Paulo: Companhia das Letras, 2020.

HARARI, Yuval Noah. Notas sobre a pandemia e breves lições para o mundo póscoronavírus. Tradução: Odorico Leal. São Paulo: Companhia das Letras, 2020. 
MORIN, Edgar. Os sete saberes necessários à educação do futuro. Tradução: Catarina Eleonora F. da Silva e Jeanne Sawaya. 2a - edição. 6ª - reimpressão São Paulo: Cortez, 2011.

OPAS. Folha informativa - COVID-19 (doença causada pelo novo coronavírus). Disponível em:

https://www.paho.org/bra/index.php?option=com_content $\&$ view=article\&id=6101: covid19\&I

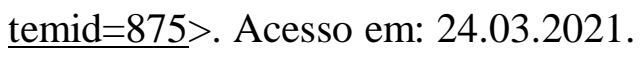

PIOVESAN, Flávia. Direitos Humanos e Justiça Internacional. 1ª - edição. São Paulo: Saraiva, 2.007.

PISARELLO, Gerardo. Globalización, constitucionalismo y derechos: las vías del cosmopolitismo jurídico In: CARBONELL, Miguel. Teoría del neoconstitucionalismo. Ensayos escogidos. Madrid: Editorial Trotta, 2007.

RODOTÀ, Stefano. Solidarietà. Un'utopia necessaria. Seconda edizione. Roma: Editori Laterza, 2016.

SANTOS, Boaventura de Sousa. A cruel pedagogia do vírus. São Paulo: Boitempo, 2020.

SEN, Amartya. A ideia de justiça. Tradução: Denise Bottmann e Ricardo Doninelli Mendes.

São Paulo: Companhia das Letras, 2.011. 